\title{
Knowledge, Attitude and Practice of nurse-midwives on the use of partograph in health care centres of Bhutan
}

\author{
Karma Choden ${ }^{1}$, Nidup Dorji ${ }^{2}$
}

${ }^{1,2}$ Faculty of Nursing and Public Health, Khesar Gyalpo University of Medical Sciences of Bhutan, Thimphu, Bhutan

\begin{abstract}
Introduction: World Health Organization recommends using partograph to reduce maternal and neonatal deaths due to obstetric complications. Proper utilization of partograph by health care providers was noted to be good when it is associated with better knowledge and a positive attitude towards partograph. There is a paucity of scientific study about knowledge, attitude and practice on the use of partograph among healthcare providers in Bhutan. Therefore, this study aimed to assess the knowledge, attitude and practice of nurse-midwives on the use and completeness of partograph in seven hospitals and one Basic Health Unit grade I. Methods: A descriptive study was carried out from September 2017 to February 2018. Non-probability sampling method was used to survey all nurse-midwives who attended deliveries in the selected health facilities using a standard semi-structured questionnaire. All partographs filled three months before the data collection was selected purposefully and reviewed using a checklist. Results: A total of 96 participants consisting of 66 (68.8\%) females and 30(31.3\%) males consented for the survey. Good knowledge of partograph was reported among $48(50 \%)$ of the participants with a mean score of 12.1 (SD: \pm 1.52 ). Attitude on the usage of partograph was found to be favorable with a median of 42 (range 32-48). Partograph usage was reported by $86(89.6 \%$ ) while only $10.4 \%$ reported having received in-service training on partograph. Out of 426 partographs reviewed, only $68(16.0 \%)$ were found to be complete. Conclusions: Despite the encouraging findings on the use of partograph, completeness of the partograph was very low. This study therefore, recommends the reinforcement of knowledge and practice through periodic continuous medical education and auditing of the partographs.
\end{abstract}

Keywords: Attitude; Completeness; Knowledge; Partograph; Practice.

\section{INTRODUCTION}

Childbirth is a natural phenomenon. Yet, everyday women die from preventable causes related to pregnancy and childbirth. In 2017 , the global point estimate of maternal death was 211 and $9.2 \%$ of which was due to direct obstetric causes ${ }^{1}$. Maternal and neonatal deaths were found to be highly associated with prolonged and obstructed labor ${ }^{2,3}$. The reported causes of maternal deaths in Bhutan were postpartum hemorrhage $(43 \%)$, sepsis $(11 \%)$, and obstructed labor $(4 \%)^{4}$. These complications can be reduced through close monitoring of women in labor using partograph ${ }^{5-7}$. Partograph, instituted by the WHO in 1987, especially for underdeveloped and developing countries, serves as an early warning system. The partograph provides a pictorial presentation of fetal and maternal wellbeing, and the progress of labor ${ }^{7}$. Despite

Corresponding author:

Karma Choden

karmachoden@fnph.edu.bt the emphasis on the use of partograph to monitor the progress of labor, a gap persists in its proper utilization. The utilization of a partograph is determined by the level of knowledge, attitude and practice of health care professionals ${ }^{8-10}$. Complete documentation of partograph is essential for monitoring the progress of labor and its outcome ${ }^{11,12}$. However, completeness remains a concerning issue. Furthermore, to the best of our knowledge, there is a paucity of scientific research regarding the assessment of knowledge, attitude and practice on the use of partograph by healthcare professionals of Bhutan. We believe that understanding the level of knowledge, attitude and practice on the use of partograph can help support the status of documented partographs for interventions, better the outcome of labor and promote maternal and child wellbeing.

Therefore, the purpose of this study was to assess the knowledge, attitude and practice of the partograph and its completeness.

\section{METHODS}

This descriptive study was conducted in hospitals in the western region of Bhutan from September 2017 - February 2018. The 
study sites were selected based on the volume of deliveries and shorter travel distance. We included seven hospitals and one BHU-I. Hence, non-probability sampling technique was used.

All the nurse-midwives who attended deliveries were surveyed using self-administered semi-structured questionnaires. There were a total of 96 nurse-midwives at the time of data collection. Nursing students, nurses on attachment duties and those who did not attend deliveries were not included in the study. The already validated data collection tool was adapted before data collection ${ }^{10}$. Retrospective review of partographs filled up three months before the survey was done. The partographs were assessed for its completeness using a checklist based on four components: Personal information of laboring woman, fetal wellbeing, the progress of labor and maternal wellbeing.

Each variable of interest was scored on the 'yes' and "no" scales. Each correct knowledge question (18 in total) earned one point, while incomplete, incorrect, or not attempted were scored zero. Respondents who scored 0-6 were categorized as having poor knowledge, whereas those that scored 7-12 and 1318 score as having fair and good knowledge, respectively. 12 questions on attitude were assessed on a 5-point Likert scale and the overall attitude was scored using median. The attitude was scored as favourable if the total scores ranged between 30-48 (indicating positive attitude towards the usage of partograph). An unfavourable attitude was considered if the scores ranged between 12-30, minimum score being 12 . Variables on practice (17 in total) were dichotomized and counted for their frequency. The questions on practice were what the participants reported on the usage of the partograph. The completeness of the partograph using the completeness checklist was reported in terms of its completeness in counts and percentages. Data entry and analysis were performed using SPSS for Windows (V22.0: IBM Corporation, Armonk, NY, USA).

The Research Ethics Board of Health, Ministry of Health, approved the conduct of this study (vide no. REBH/ Approval/2017/030).

\section{RESULTS}

\section{Characteristics of nurse-midwives}

Table 1 shows that $68.8 \%$ of the participants were females and $70.8 \%$ of them were in the age range of $25-35$ years. Sixty-three $(65.6 \%)$ had the professional qualification of General Nurse Midwife. Regarding clinical experiences, 80(83.3\%) had a clinical experience of fewer than 10 years while $10(10.4 \%)$ of them had clinical experience ranging from 15-20 years.

\section{Knowledge on Partograph}

The knowledge about the partograph was assessed through 18 items measured on the 'yes' and 'no' scale. Among 96 nursemidwives, $95(99.0 \%)$ knew what was a partograph while $95.8 \%$ reported that a partograph should be used during labour. As evident from Table 2, they lacked knowledge on desired frequency $(61.1 \%)$ and duration of uterine contractions (33.3\%)
Table 1. Demographic characteristics, Professional qualifications and number of year of service among the nurse-midwives in seven hospitals and one BHU-I* in Bhutan from September 2017 - February $2018(n=96)$

\begin{tabular}{ll} 
Characteristics & Number (\%) \\
\hline Sex & \\
Male & $30(31.2)$ \\
Female & $66(68.8)$ \\
Age in Years & \\
Below 25 & $14(14.6)$ \\
$25-35$ & $68(70.8)$ \\
$35-45$ & $13(13.6)$ \\
More than 45 & $1(1.0)$ \\
Professional qualification & \\
Assistant Nurse & $20(20.8)$ \\
General Nurse midwives & $63(65.6)$ \\
Bachelor's Degree & $11(11.5)$ \\
Master's Degree & $2(2.1)$ \\
Numbers of years in services & \\
Less than 10 & $80(83.3)$ \\
$10-15$ & $4(4.2)$ \\
$15-20$ & $10(10.4)$ \\
More than 20 & $2(2.1)$ \\
\hline
\end{tabular}

"Basic Health Unit

for normal labour and the function of the alert line. Although $100 \%$ of the participants reported that the progress of labour is assessed by the degree of cervical dilatation and descent of the presenting part, $13.6 \%$ of participants reported not knowing if prolonged labour refers to more than 12 hours of labour. Overall, $50 \%$ of them had a good knowledge on partograph with a median score of 12.5 (Min-Max: 10-16), while 50\% scored fair. There was no difference between the knowledge on partograph among males and females as shown in Table 2.

\section{Attitude on the utilization of partograph}

All the participants $(100 \%)$ had a favorable attitude towards the partograph with a median score of 42 (Min-Max: 32 - 48). $87.5 \%$ strongly agreed that they used partograph daily in their practice, as evident from Table 3 . However, only $49 \%$ reported being very confident in the use of the partograph. Although the majority (80.2\%) knew the importance of using a partograph, $76 \%$ reported that a partograph is not necessary to monitor the progress of labor.

\section{Utilization of partograph}

As illustrated in Table 4, all the participants reaffirmed the availability of partograph at all times in their ward/unit. Although $97.9 \%$ reported using partograph to monitor women in labour, $2.1 \%$ (2 participants) felt that it was not necessary to use 
Table 2. Knowledge on the assessment of labour using partograph among the nurse-midwives in seven hospitals and one BHU-I in Bhutan from September 2017 - February $2018(n=96)$

\begin{tabular}{ll}
\hline Characteristics & $\boldsymbol{n}(\boldsymbol{\%})$ \\
\hline Do you know what partograph is? & \\
$\quad$ Yes & $95(100.0)$ \\
When is a partograph used? & \\
$\quad$ Before labor & $4(4.2)$ \\
$\quad$ During labor & $92(95.8)$
\end{tabular}

In the normal progress of labor:

The graph on the partograph should fall to the left of the alert line

$\begin{array}{ll}\text { Yes } & 64(66.7) \\ \text { No } & 31(32.3) \\ \text { Don't know } & 1(1.0)\end{array}$

The graph/plot on the partograph should fall on the alert line $(n=95)$

$\begin{array}{ll}\text { Yes } & 55(57.9) \\ \text { No } & 38(40.0) \\ \text { Don't know } & 2(2.1)\end{array}$

During labor:

Three contractions in every minute are normal

$\begin{array}{ll}\text { Yes } & 38(39.6) \\ \text { No } & 58(60.4)\end{array}$

Minimum duration of a strong contraction is 40 seconds (n=94)

Yes 64 (66.7)

No 32 (33.3)

Progress of labor is assessed by degree of cervical

dilatation and descent of presenting part

Yes 96 (100.0)

Labor is prolonged when it lasts more than 12 hours

Yes

$82(85.4)$

No

Don't know

Final knowledge score

$\begin{array}{lll}\text { Poor }(0-6) & & 0(0.0) \\ \text { Fair }(7-12) & & 48(50.0) \\ \text { Good }(13-18) & & 48(50.0) \\ \text { tal knowledge score } & \text { Mean } \pm \text { SD } & \boldsymbol{p} \text {-value } \\ \text { Male }(n=30) & 12.53 \pm 1.76 & 0.082 \\ \text { Female }(n=66) & 12.64 \pm 1.41 & \end{array}$

Table 3. Attitude on the utilization of partograph among the nurse-midwives in seven hospitals and one BHU-I in Bhutan from September 2017 - February 2018 ( $n=96)$

\begin{tabular}{|c|c|}
\hline Components & $n(\%)$ \\
\hline You use partograph daily in your practice & $84(87.5)$ \\
\hline $\begin{array}{l}\text { Partograph is useful for reducing maternal } \\
\text { deaths }\end{array}$ & $77(80.2)$ \\
\hline $\begin{array}{l}\text { Partograph is not useful for reducing mater- } \\
\text { nal morbidity }\end{array}$ & $45(47.4)$ \\
\hline Partograph reduces neonatal deaths & $69(72.6)$ \\
\hline $\begin{array}{l}\text { Neonatal morbidity can be reduced by using } \\
\text { partograph }\end{array}$ & $50(52.6)$ \\
\hline $\begin{array}{l}\text { Efficiency of professionals attending women } \\
\text { in labor can be increased by use of parto- } \\
\text { graph }\end{array}$ & $55(57.9)$ \\
\hline $\begin{array}{l}\text { To improve the quality of care for women in } \\
\text { labor using partograph is mandatory }\end{array}$ & $83(86.5)$ \\
\hline I am very confident to use partograph & $47(49.0)$ \\
\hline $\begin{array}{l}\text { If one has served as a midwife for long, they } \\
\text { will be able to plot partograph completely } \\
\text { and accurately }\end{array}$ & $54(56.8)$ \\
\hline $\begin{array}{l}\text { I think partograph is not necessary to moni- } \\
\text { tor the progress of labor }\end{array}$ & $73(76.0)$ \\
\hline $\begin{array}{l}\text { I wish there was no such thing as a parto- } \\
\text { graph, a document that consumes lots of our } \\
\text { time }\end{array}$ & $67(69.8)$ \\
\hline $\begin{array}{l}\text { Partograph can be filled up during anytime } \\
\text { of the labor }\end{array}$ & $40(41.7)$ \\
\hline $\begin{array}{l}\text { Total knowledge Median }=42.00 \quad(\mathrm{~min}-\mathrm{m} \\
\text { score }\end{array}$ & $\operatorname{ax}: 32.00-48.00)$ \\
\hline
\end{tabular}

partograph in all women in labour, the reason being that some women may be in the latent phase of labor or are having false labor pain. Majority (97.9\%) reported that they start plotting the partograph when the cervix is four centimeters dilated. However, 2.1\% (2 participants) reported that they start plotting partograph when the cervix is eight centimeters dilated. Majority of the participants mentioned that they can deduce and interpret abnormal partograph findings. $51.0 \%$ participants reported having received training on usage of partograph. However, 52.1\% reported receiving such training only during their educational preparation while $10.4 \%$ had received in-service training.

\section{Completeness of partograph}

A total of 426 partographs were assessed from all eight health care centers. Of the four components assessed, maternal information received the least attention as evident from Table 5. Only 17.8\% had complete maternal information and $10.8 \%$ were left blank. Fetal wellbeing was completely assessed in $26.3 \%$ of the assessed 
Table 4. Practice on the use of the partograph among the nurse-midwives in seven hospitals and one BHU-I in Bhutan from September 2017 - February $2018(n=96)$

Practice component $n(\%)$

Is partograph available in your labor ward at the present time?

Yes

No

$96(100.0)$

$0(0.0)$

I use partograph during labor in

Less than $25 \%$ of pregnant women I attend to

$$
25-50 \%
$$

$50-75 \%$

$75-99 \%$

$100 \%$

\section{When do you start plotting partograph?}

1. When cervix is four centimeters dilated

2. When cervix is eight centimeters dilated

Which of the following assessment can you make with the partograph?

1. Obstructed labor

2. Prolonged labor

3. Poor progress of labor

4. Insufficient uterine contraction

5. Suspected fetal distress

6. Abnormal fetal heart rate

7. Satisfactory progress of labor

8. Need for augmentation of labor

9. Need for caesarean section

10. Dehydration in the mother

Training during their educational preparation

In-service training on partograph

partographs; the components that were missed or incomplete included fetal heart rate, amniotic fluid status and fetal head moulding. Labor progress was better recorded as compared to other components with $58.5 \%$ of the assessed partographs being complete. The components that received less attention were the record of uterine contractions every 30 minutes and descent of the presenting part at every vaginal examination. Although $33.6 \%$ of the partographs had complete maternal wellbeing components, maternal pulse and the body temperature recordings were not paid much attention to. Overall, the completeness of the partographs was found to be only $16.0 \%$.
Table 5. Completeness of the partograph in seven hospitals and one BHU-I in Bhutan from Septemper 2017 February $2018(n=426)$

\begin{tabular}{ll}
\hline Personal Information & N (\%) \\
\hline Name & $372(87.3)$ \\
$\quad$ Yes & $54(12.7)$ \\
No & \\
Parity & $374(87.8)$ \\
$\quad$ Yes & $52(12.2)$ \\
No & \\
Ruptured membrane & $184(43.2)$ \\
$\quad$ Yes & $242(56.8)$ \\
$\quad$ No & \\
Overall completeness of personal information & \\
$\quad$ Complete & $76(17.8)$ \\
Incomplete & $304(71.4)$ \\
Not recorded & $46(10.8)$ \\
Fetal heart rate recorded every 30 minutes & \\
$\quad$ Yes & $363(85.2)$ \\
No & $63(14.8)$ \\
Amniotic fluid & \\
$\quad$ Yes & $297(69.7)$ \\
$\quad$ No & $129(30.3)$ \\
Moulding & \\
$\quad$ Yes & $235(55.2)$ \\
No & $191(44.8)$ \\
Overall completeness of fetal wellbeing & \\
Complete & $112(26.3)$ \\
Incomplete & $302(70.9)$ \\
Not recorded & $12(2.8)$ \\
Yervical dilatation & \\
$\quad$ Nes & $422(99.1)$ \\
No & $4(0.9)$
\end{tabular}

No 4(0.9)

Descent of head recorded at every per vaginal examination

Yes

No

Uterine contraction recorded every 30 minutes Yes No $68(16.0)$

Overall completeness of the progress of labor Complete Incomplete Not recorded

Maternal pulse recorded every 30 minutes Yes No

Maternal blood pressure Yes No

Maternal temperature Yes No

$249(58.5)$ $174(40.8)$ $3(0.7)$

216(50.7) $210(49.3)$

$382(87.7)$ 44(10.3)

$321(75.4)$

$105(24.6)$

Over all completeness of the maternal wellbeing record

Complete

Incomplete

Not recorded

$143(33.6)$

$258(60.6)$

25(5.9)

Overall completeness of the partograph

Complete

$68(16.0)$

Incomplete

Not recorded

$330(77.5)$

20(4.7)

$8(1.8)$ 


\section{DISCUSSION}

A total of 96 nurse-midwives attending deliveries were recruited for the survey on knowledge, attitude and practice of partograph. In addition, a total of 426 partographs were reviewed for its completeness.

The findings on knowledge in this study suggest that overall, nurse-midwives have a good knowledge regarding the partograph. Out of 96 nurse-midwives, 50\% of them had 'good knowledge' and $50 \%$ had 'fair knowledge' which is significantly higher than what was reported in Addis Ababa $(39.0 \%)^{10}$, Cameroon $(29.6 \%)^{9}$, and Samdrup Jongkhar $(7.1 \%)^{11}$ although, slightly lower than the ones reported by a study carried out in Northwest Ethiopia $(56.1 \%)^{13}$. These differences in knowledge could be due to study settings, knowledge assessment tools that were used, level of training on partographs that were received, extent of knowledge gained during their education, number of years in service and their qualifications. This may also imply that having 'fair to good knowledge' does not ensure adequate knowledge on the partograph and its completeness. For instance, $100 \%$ of the participants in this study knew that the progress of labour was determined by cervical dilatation and descent of the presenting part, however it is concerning to note that they are not able to correctly report the desired frequency and duration of uterine contractions, function of the alert line and the definition of prolonged labour.

Attitude is another factor that enhances knowledge and usage of the partograph. Although attitude towards using partograph was found to be favourable (Score of 42 ), $76 \%$ of them reported that partograph is not necessary to monitor the progress of labour and only $49 \%$ reported being confident in the use of partograph. Favourable attitude towards using partograph is comparable to the study in Ethiopia ${ }^{13}$. Utilization of partograph was reported as high (89.7\%) by the participants which is in line with the study done in Ethiopia ${ }^{10,15}$. However, some participants (2.1\%) expressed that a partograph is not necessary to be used in all the women in labour. With only $10.4 \%$ receiving in-service training on partograph, this could have had an impact on its utilization in Bhutan ${ }^{11}$. Majority of the participants (89.7\%) reported utilizing partograph to monitor women during labour and start plotting partograph once the cervical dilatation is $4 \mathrm{~cm}$ and above $(97.9 \%)$, yet inconsistency in actual utilization could be noticed from the review of the filled partographs, similar to the findings of a study carried out in Nigeria ${ }^{15}$. The factors responsible for the mismatch between what is reported and what is done in actual practice needs to be explored further. Out of 426 partographs assessed, $16.0 \%$ was found to be complete, $77.5 \%$ was incomplete, $1.8 \%$ was referred to higher centers and $4.7 \%$ were left empty. This finding is consistent with the findings of the study carried out in 2017 in Bhutan ${ }^{11}$ and could be attributed to trainings they have received during their professional career and the knowledge they have on the partograph.

This study has some limitations. There may be many factors such as knowledge, attitude, years of service and the participant's place/county of pre-service education which may be associated with proper utilization, which is not explored in this study. The other important limitation of this study was the fact that it was not able to establish the relationship between the participants' knowledge and attitude to the completeness of the partograph and the relationship between the reported utilization of partograph and actual completeness of the partograph.

\section{CONCLUSIONS}

This study implicates that despite having fair to good knowledge, a favourable attitude and highly reported utilization of partograph, a gap remains when it comes to actual practice as evidenced by the low completeness of partographs. Taking into consideration the various limitations of the study, we recommend a further detailed study on the factors associated with incompleteness of the partograph. Nonetheless, the results from this study can be used to reinforce the use of partograph through continuous medical education, auditing of the partographs and taking up the utilization of partograph as a point of care quality improvement (POCQI) projects in their respective units or hospitals.

\section{ACKNOWLEDGEMENTS}

We would like to thank all the participants of this study. The authors also would like to express our gratitude to the Director (MECRIT) and KGUMSB for their patience and support.

\section{REFERENCES}

1. WHO. Maternal mortality: level and trends 2000 to 2017 [Internet]. Sexual and Reproductive Health. 2019. 12 p. [Full Text]

2. Say L, Chou D, Gemmill A, Tunçalp Ö, Moller AB, Daniels $\mathrm{J}$, et al. Global causes of maternal death: A WHO systematic analysis. Lancet Glob Heal. 2014;2(6):323-33. [Full Text | DOI]

3. Lawn J, Shibuya K, Stein C. No cry at birth: Global estimates of intrapartum stillbirths and intrapartum-related neonatal deaths. Bull World Health Organ. 2005;83(6):409-17. [Full Text]

4. Dorji P, Lethro P, Tshering L, Tshomo T. Situation of maternal health in Bhutan 2018. Bhutan Heal J. 2018;4(2):39-42. [Full Text | DOI]

5. Lavender T, Bernitz S. Use of the partograph - Current thinking. Best Pract Res Clin Obstet Gynaecol [Internet]. 2020;67:33-43. [Full Text | DOI]

6. Lavender T, Cuthbert A, Smyth RMD. Effect of partograph use on outcomes for women in spontaneous labour at term and their babies. Cochrane Database Syst Rev. 2018;2018(8). [Full Text | DOI]

7. WHO. Education material for teachers of midwifery [Internet]. 2nd ed. World Health Organization; 2008. [Full Text] 
8. Zelellw DA, Tegegne TK. Level of partograph utilization and its associated factors among obstetric caregivers at public health facilities in East Gojam Zone, Northwest Ethiopia. PLoS One. 2018;13(7):1-13. [Full Text | DOI]

9. Sama CB, Takah NF, Danwe VK, Melo UF, Dingana TN, Angwafo FF. Knowledge and utilization of the partograph: A cross-sectional survey among obstetric care providers in urban referral public health institutions in northwest and southwest Cameroon. PLoS One. 2017;12(2):1-14. [Full Text | DOI]

10. Engida Y, Berhanu D, Ayalew ANF. Knowledge and utilization of partograph among obstetric care givers in public health institutions of Addis Ababa, Ethiopia - Academic Article. 2013;1-9. [Full Text | DOI]

11. Kuenzang, Pokhrel HP, Dorji K, Rinzin D. Knowledge of Partograph Recording and Interpretation and Its Documentation Status in Samdrup Jongkhar District, Bhutan. Int J Innov Res Med Sci. 2018;3(12):3-8.
12. Mandiwa $\mathrm{C}$, Zamawe C. Documentation of the partograph in assessing the progress of labour by health care providers in Malawi's South-West zone. Reprod Health. 2017;14(1):1-7. [Full Text | DOI]

13. Zelellw DA, Tegegne TK, Getie GA. Knowledge and Attitude of Obstetric Care Providers on Partograph and Its Associated Factors in East Gojjam Zone, Northwest Ethiopia. Adv Med. 2016;2016:1-8. [Full Text | DOI]

14. Wakgari N, Amano A, Berta M, Tessema GA. Partograph utilization and associated factors among obstetric care providers in north shoa zone, central ethiopia: A cross sectional study. Afr Health Sci. 2015;15(2):552-9. [Full Text | DOI]

15. Opiah MM, Ofi AB, Essien EJ, Monjok E. Knowledge and utilization of the partograph among midwives in the Niger Delta Region of Nigeria. Afr J Reprod Health. 2012;16(1):125-32. [Full Text]

\section{AUTHORS CONTRIBUTION}

Following authors have made substantial contributions to the manuscript as under:

KC: Concept, design, data collection and analysis, manuscript writing and review.

ND: Design, data collection and analysis, manuscript writing and review

Author agree to be accountable for all respects of the work in ensuring that questions related to the accuracy and integrity of any part of the work are appropriately investigated and resolved.

\section{CONFLICT OF INTEREST}

None

GRANT SUPPORT AND FINANCIAL DISCLOSURE

Bhutan Foundation 